\title{
Discriminación interseccional, desarrollo del concepto, inclusión en la jurisprudencia del Sistema Internacional de Protección de Derechos Humanos, el concepto en la jurisprudencia nacional
}

\author{
Intersectional Discrimination, Development of the Concept, Inclusion in \\ International Human Rights Protection Courts, the Concept in the Chilean \\ Jurisprudence
}

Dominnique LUAN RAMOS 1

Resumen: Sobre el desarrollo doctrinal y jurisprudencial del concepto de discriminación interseccional, la relación entre la discriminación interseccional y discriminación estructural, y su inclusión en la jurisprudencia de la Corte Suprema chilena.

Palabras clave: Discriminación interseccional, Discriminación múltiple, Discriminación estructural, Interseccionalidad

\begin{abstract}
About the doctrinal and jurisprudential development of the concept of intersectional discrimination, the relationship between intersectional discrimination and structural discrimination, and its inclusion in the Chilean Supreme Court jurisprudence.
\end{abstract}

Keywords: Intersectional Discrimination, Multiple Discrimination, Structural Discrimination, Intersectionality

\footnotetext{
${ }_{1}^{1}$ Magíster en Derecho Constitucional mención derecho procesal constitucional, Centro de Estudios Constitucionales de Chile, Universidad de Talca. Actualmente cursando programa de Doctorado en Derecho, Universidad de Talca. Correo electrónico dominnique.luan@gmail.com
} 


\section{Introducción}

La discriminación interseccional es una diferencia irracional, subjetiva y desproporcionada de trato basada en dos o más causales de discriminación las cuales concurren conjuntamente. Por lo que un mismo acto discriminatorio posee fundamentos compuestos cuya interacción crea una situación discriminatoria, que, al atacar diversos elementos de la identidad del sujeto, presenta una afrenta particular y agravada a su dignidad.

Existen una serie de conceptos relacionados con la discriminación interseccional, ligados principalmente al desarrollo del principio de igualdad ante la ley y prohibición de discriminación, evolución que ha contribuido en forma directa al tema principal de esta investigación. Debido a ello requieren ser analizados someramente previo al análisis de la discriminación interseccional en un sentido conceptual y posteriormente su inclusión en la jurisprudencia tanto internacional como de nuestra Corte Suprema.

Dichos conceptos son: igualdad, igualdad ante la ley y prohibición de discriminación; categorías prohibidas y criterios sospechosos de discriminación. Posteriormente se analizará la vulnerabilidad y fragilidad humana y los grupos vulnerables, todos los cuales, como se observará se encuentran íntimamente relacionados con las causales estructurales de discriminación que componen a la discriminación interseccional.

\section{Igualdad, igualdad ante la ley y prohibición de discriminación}

Para Ferrajoli "la igualdad jurídica no será otra cosa que la idéntica titularidad y garantía de los mismos derechos fundamentales independiente del hecho, e incluso precisamente por el hecho de que los titulares entre sí son diferentes"2.

El principio de igualdad conlleva necesariamente dos consecuencias desde el punto de vista legal; en un primer término se deriva la denominada

igualdad en la ley, [la cual] es una exigencia constitucional dirigida en principio al legislador y se traduce en que, en el ejercicio de sus potestades legislativas, le está prohibido imponer diferencias, establecer equiparaciones o introducir desequilibrios e inequidades procesales en los derechos y obligaciones [...], si ellas no están o son, normativa y públicamente justificables, desde un punto de vista constitucional $[\ldots]^{3}$.

${ }^{2}$ Ferrajoli (2004), p. 82.

${ }^{3}$ Gómez y Figueroa (2000), p. 149. 
Existe además otra dimensión de la igualdad, denominada igualdad en la aplicación de la ley. En este caso, se tutela constitucionalmente que a los destinatarios de las normas jurídicas se les haga aplicación de los criterios o diferencias “[...] que contenga la norma de modo imparcial y sin efectuar discriminaciones que no estén previstas en ella"4.

Corresponde tratar un segundo subprincipio emanado de la igualdad, la denominada igualdad material, la cual, en forma somera, encuentra su fundamento en el reconocimiento de la existencia de individuos desventajados quienes son titulares de las denominadas medidas de discriminación positiva, las cuales tienen por objeto equiparar las condiciones de aquellos que han sufrido una desventaja en el ejercicio de sus derechos. Al respecto la Comisión IDH señala que

[e]l sistema interamericano [...] avanza hacia un concepto de igualdad material o estructural que parte del reconocimiento de que ciertos sectores de la población requieren la adopción de medidas especiales de equiparación. Ello implica la necesidad de trato diferenciado cuando, debido a las circunstancias que afectan a un grupo desaventajado, la igualdad de trato suponga coartar o empeorar el acceso a un servicio, bien o el ejercicio de un derecho ${ }^{5}$.

"No se trata sólo de tratar igual a todos, sino también de tratar desigualmente a los desiguales, en proporción a su desigualdad"6.

\subsection{CATEGORÍAS PROHIBIDAS Y CRITERIOS SOSPECHOSOS DE DISCRIMINACIÓN}

Como se mencionó en el apartado anterior, existen grupos de personas que, debido a una característica, sea ella física o social, se encuentra en desventaja al momento de ejercer sus derechos. Esta realidad no es desconocida para las ciencias jurídicas, razón por la cual se crearon los conceptos de categorías prohibidas de discriminación, que son aquellas consagraciones positivas de la prohibición de realizar diferenciaciones de carácter irracional, subjetiva y desproporcionada debido a ellas. Y, de igual forma se ha generado el concepto de categoría sospechosa de discriminación, en base a la cual en el caso que se sospeche de un tratamiento injusto basado en la pertenencia a un grupo vulnerable o basada en un criterio prohibido, se debe aplicar un escrutinio estricto del acto supuestamente discriminatorio, con el fin de verificar su constitucionalidad.

${ }^{4}$ Gómez y Figueroa (2000), p. 149.

${ }^{5}$ Comisión Interamericana Derechos Humanos, "Acceso a la justicia para las mujeres víctimas de violencia en las Américas" de 20 de enero de 2007, párrafo 99.

${ }^{6}$ Falcón (2008), p. 247. 


\subsubsection{DERECHOS VULNERADOS}

Para efectos del presente trabajo se entenderá por categoría prohibida de discriminación a aquellas sobre las cuales el ordenamiento jurídico ha generado una protección especial, prohibiendo diferenciaciones basadas en ellas. Referidas a

[...] aquellos supuestos en los que el criterio o rasgo de diferenciación de trato jurídico es la raza, el origen étnico, el sexo, la religión, la ideología, el nacimiento o cualquier otro que la experiencia histórica evidencie como proclives para configurar una diferencia peyorativa entre las personas, basada en prejuicios gravemente odiosos para la dignidad de la persona ${ }^{7}$.

Tradicionalmente, desde el comienzo de la reglamentación interamericana contra la discriminación se entendía que estas hacían “[...] referencia a motivos inmutables o inmodificables por la propia voluntad de la persona o bien a factores históricos asociados con prácticas discriminatorias de antigua data"8. La noción tradicional de categoría prohibida fue ampliada en la Opinión Consultiva sobre la Condición Jurídica de los Trabajadores Migrantes, que constituye el análisis más completo realizado por parte de la Corte Interamericana en materia de discriminación, donde se indicó que no son admisibles los tratos discriminatorios en perjuicio de ninguna persona por motivos de género, raza, color, idioma, religión o convicción, opinión política o de otra índole, origen nacional, étnico o social, nacionalidad, edad, situación económica, patrimonio, estado civil, nacimiento o cualquier otra condición.

\subsubsection{CRITERIOS SOSPECHOSOS DE DISCRIMINACIÓN}

Concepto surgido en Estados Unidos, donde la Corte Suprema elaboró la doctrina del denominado escrutinio estricto para determinar si una regulación vulneraba o no la igualdad ante la ley. Dicha doctrina surgió en el fallo United States v. Carolene Products Co. donde se sentó de forma imperceptible un precedente, referido a minorías discretas o insulares, las cuales

[...] son grupos minoritarios que no están determinados previamente sino que deben identificarse en un contexto específico debido a que es probable que algunos de estos grupos logren una inclusión social mientras otros continúan con la exclusión o que, simplemente, aparezcan nuevos grupos que se ubiquen en esa situación ${ }^{9}$.

En relación con dichas minorías se terminó por acuñar el denominado escrutinio estricto en el caso Toyosaburo Korematsu v. United States. Este escrutinio estricto “[...] se aplica, por

\footnotetext{
${ }^{7}$ Rey (2017), p. 136.

${ }^{8}$ Dulitzky (2007), p. 17.

${ }^{9}$ Romero (2011), p. 159.
} 
ejemplo, cuando desde el planteo de la cuestión igualitaria se "sospecha" que la exclusión es injustificada e inconstitucional, porque afecta a un grupo de personas que históricamente ha sido discriminado y que las consecuencias perjudiciales para sus derechos persisten en la actualidad" 10 .

Se señala que con estas "[...] intercambiables expresiones "categorías sospechosas" y "criterios sospechosos" [...] se alude a ciertas propiedades, características, rasgos o condiciones predicables de las personas que en los hechos o en el Derecho han estado históricamente relacionadas con un trato discriminatorio, como el sexo o la raza"11. Y como consecuencia "[...] encuentran especiales dificultades para ejercitar con plenitud los derechos reconocidos por el ordenamiento jurídico [...]"12.

En relación con el tratamiento que deben tener las autoridades cuando se presenta una discriminación basada en uno de estos criterios se señala que

[...] la violencia de la que son víctimas no puede ser investigada con los mismos criterios y estándares que se utilizan frente a la de cualquier otro tipo. No solo porque ello puede enmascarar que el origen de la violencia es precisamente un elemento discriminatorio, sino también porque no consideran las situaciones particulares de la víctima, tales como su género, su cultura, su lengua. Esto puede constituirse en un factor adicional de revictimización y, a la vez, puede llevar a una investigación ineficaz e inoperante ${ }^{13}$.

El rechazo a distinciones fundadas en estas "categorías sospechosas" se ha convertido en norma de jus cogens internacional. Hasta el momento el referido consenso se ha centrado en el rechazo a diferenciaciones de trato basadas en la raza, el sexo o la religión de la persona. De esta manera se puede decir que hay una carga probatoria más pesada para aquellos que pretenden legitimar una medida que implica una desventaja ${ }^{14}$.

"[...] requiriéndose "razones de peso" para justificar diferencias de trato basadas en estas clasificaciones" 15 .

\subsection{VULNERABILIDAD, FRAGILIDAD, GRUPOS VULNERABLES}

En el presente apartado se tratará, en primer lugar, el concepto de vulnerabilidad y grupos vulnerables, para, a continuación, analizar de forma somera el concepto de discriminación estructural, ello debido a su interrelación con la discriminación interseccional.

${ }^{10}$ Clérico y Aldao (2011), p. 229.

${ }^{11}$ Díaz (2013), p. 643.

${ }^{12}$ Tracey (2011), p. 199.

${ }^{13}$ Dulitzky (2007), p. 31.

${ }^{14}$ Palacios (2006), pp. 36 y 37.

${ }^{15}$ Arnardóttir (2003), p. 204 T. del A. 


\subsubsection{VULNERABILIDAD}

Cuando hablamos de vulnerabilidad normalmente entendemos que se trata de aquello que puede recibir daño. En un contexto humano se observa la vulnerabilidad como una relación entre la posibilidad de recibir daño o riesgo y el daño efectivamente causado. Dicha vulnerabilidad puede provenir de una condición del sujeto (condición sexual, discapacidad, género, etc.) o de una situación específica (migrantes, damnificados, personas en zonas de conflictos etc.). "El término vulnerabilidad es siempre relativo y específico con respecto a una amenaza particular subyacente "[...] solo es posible hablar de un grado de vulnerabilidad desde el punto de vista de la probabilidad de la amenaza y en función de su intensidad particular, de su frecuencia y de su duración"16.

Es parte de la naturaleza humana el ser vulnerable y ello va más allá de un plano físico. El ser humano puede ser vulnerable desde un punto de vista económico, social, sexual, etario entre muchos otros. Como consecuencia de dicha vulnerabilidad reciben un daño o bien se encuentran en una posición de riesgo, lo que finalmente se traduce en una desmejora al momento de desenvolverse en el plano social, sea ello entre sus pares ciudadanos o cuando se relacionan con el Estado.

Si bien la vulnerabilidad forma parte de la naturaleza humana, en cuanto al origen de esta podemos distinguir entre las personas en situación de vulnerabilidad, los cuales podemos definir como sujetos que se encuentran temporalmente en una situación donde son vulnerables, la cual puede acabar o modificarse a través del tiempo. Existen, por otra parte, colectivos humanos cuya vulnerabilidad es constante, dicha vulnerabilidad radica en una circunstancia inalterable, o, a lo menos, en una situación estable en el tiempo.

\subsubsection{GRUPOS VULNERABLES}

Entendiendo que todos los seres humanos podemos eventualmente encontrarnos en una situación de vulnerabilidad, corresponde analizar la situación en que se encuentran ciertos grupos de individuos quienes debido a una condición inalterable propia de su naturaleza han sido históricamente discriminados y excluidos. Se señala que la observancia de "cualquiera de

${ }^{16}$ Blaikie (1996), p. 92. 
estas cinco condiciones [explotación, marginación, carencia de poder, imperialismo cultural y violencia] [es] suficiente para decir que un grupo está oprimido ${ }^{17}$.

Como consecuencia de la aspiración de igualdad material “[...]los Estados, a través de políticas públicas especiales, generen acciones afirmativas de inclusión con el fin de equiparar las condiciones de desequilibrio que [...] han impedido el goce efectivo de los derechos de los sujetos o grupos en condiciones menos favorables, esto es de especial protección”18. Esta obligación, si bien atañe a la institucionalidad toda, recae particularmente en el legislador sobre quien pesa el deber de no producir leyes que pudiesen resultar "[...] ajenas, ciegas o insensibles al hecho de que existen muchas personas en situación de desventaja inmerecida por motivo de su adscripción grupal, y a que este dato las hace vulnerables a la discriminación[...]”19.

La pertenencia a un grupo social moldea la relación e identidad del sujeto puesto que incide en la forma en que la sociedad y el mismo se percibe. La característica que encasilla al sujeto en uno de estos grupos le adscribe de igual forma a una condición social que le hace susceptible de sufrir discriminación en todos los ámbitos de su vida, llegando a afectar aspectos tan disimiles como el acceso a oportunidades, empleabilidad e incluso su autopercepción. Los estereotipos que acompañan a muchos de estos grupos acaban relacionándose con la vulneración de garantías al producirse “[...] "un trato igual o distinto basado en el prejuicio que sufren personas pertenecientes a ciertos grupos sociales y que ocasiona, o puede producir, una privación del goce de ciertos derechos" 20 .

La pertenencia a estos grupos desventajados conlleva una discriminación de carácter histórico, permanente y muchas veces desapercibida que termina por causar una constante herida en la dignidad del sujeto, la cual afecta todos los aspectos sociales de su vida.

\subsection{DISCRIMINACIÓN ESTRUCTURAL}

El concepto de discriminación estructural "es una propuesta doctrinal dirigida a redefinir el concepto jurídico tradicional de discriminación y a dar cabida en su denotación a la noción de opresión intergrupal”21, es decir, se trata de aquella discriminación sufrida históricamente por parte de algunos colectivos fundamentada en una característica común. Como será analizado al

\footnotetext{
17 Young (2000), p. 84.

${ }_{18}$ Bernal y Padilla (2018), p. 48.

${ }^{19}$ Rodríguez (2007), p. 70.

${ }^{20}$ Esparza (2019), p. 9.

${ }^{21}$ Barrère y Morondo (2011), p. 17.
} 
momento de referirnos a la discriminación interseccional, es observable que las personas en quienes concurre más de una causal de discriminación, una de ellas, a lo menos, posee este carácter.

En cuanto a la relación que une a la discriminación estructural con los grupos vulnerables, el Comité de Derechos Económicos, Sociales y Culturales

[...] ha constatado periódicamente que la discriminación contra algunos grupos subsiste, es omnipresente, está fuertemente arraigada en el comportamiento y la organización de la sociedad y a menudo implica actos de discriminación indirecta o no cuestionada. Esta discriminación sistémica puede consistir en normas legales, políticas, prácticas o actitudes culturales predominantes en el sector público o privado que generan desventajas comparativas para algunos grupos y privilegios para otros ${ }^{22}$.

Algunos ejemplos de las consecuencias negativas que trae a los sujetos la denominada discriminación estructural son

[...] la violencia policial marcada por el sesgo social o racial, el hacinamiento y la tortura en los sistemas carcelarios, cuyas víctimas habituales son los jóvenes de sectores populares; las prácticas generalizadas de violencia doméstica contra las mujeres, toleradas por las autoridades estatales; la privación de la tierra y de la participación política de los pueblos y comunidades indígenas; la discriminación de la población afrodescendiente en el acceso a la educación y a la justicia; el abuso de las burocracias contra los inmigrantes indocumentados; los desplazamientos masivos de población rural en contextos de violencia social o política ${ }^{23}$.

Con el empleo de medidas tendientes a equiparar la situación de aquellos grupos desventajados "[...] se avanza desde una idea de igualdad como no discriminación, a una idea de igualdad como protección de grupos subordinados [...] y se desplaza hacia una noción de igualdad sustantiva, que demanda del Estado un rol activo para generar equilibrios sociales, la protección especial de ciertos grupos que padecen procesos históricos o estructurales de discriminación"24. Permitiendo con ello el correcto desarrollo de las personas integrantes de estos colectivos y su inclusión en la vida social en condiciones de igualdad en relación con sus conciudadanos. Torbisco se refiere a la realidad que viven las personas pertenecientes a un grupo vulnerable estructuralmente discriminado señalando que

[p]ara decirlo sin rodeos, existen jerarquías de estatus en todas las democracias occidentales que sugieren que es mejor ser cristiano que musulmán, blanco que negro, heterosexual que homosexual, hombre que mujer, etc. Estas concepciones basadas en prejuicios infundados

\footnotetext{
${ }^{22}$ Comité de DESC, Observación General № 20, La no discriminación y los derechos económicos, sociales y culturales, 2009, párrafo 12.

${ }^{23}$ Abramovich (2009), p. 17.

${ }^{24}$ Abramovich (2009), p. 18.
} 
estratifican a la sociedad y degradan y estigmatizan a los poseedores de identidades devaluadas ${ }^{25}$.

De igual forma, Saba relata cómo dichos perjuicios escapan incluso a sociedades donde se toman medidas antidiscriminación por medio del ejemplo de una orquesta, donde las audiciones se realizan a ciegas con el fin de aumentar la paupérrima presencia femenina en dicho arte, sin embargo y a pesar de dichas medidas acaba por concluir que

[...] algunas sociedades asignan informalmente a las mujeres un rol social limitado, por ejemplo, a las actividades domésticas. Si damos por sentado que -hasta el momento de la selección bajo análisis- la mayoría de las orquestas no contaba con mujeres, éstas podrían haber supuesto que, incluso de ser aceptadas, su situación no sería sencilla, ya que deberían enfrentar prejuicios y maltratos cotidianos en el ejercicio de sus obligaciones ${ }^{26}$.

Se modifica, de igual forma, la aplicación del denominado juicio de igualdad como elemento probatorio de la discriminación alegada, tradicionalmente "corresponde a quien afirma haber sido tratado desigualmente suministrar un término comparativo que permita llegar a la conclusión de que ha sido tratado de forma injustificadamente desigual que otros que se hallan en idéntica situación y, por ende, de que ha sido discriminado"27. Puesto que la discriminación estructural posee una naturaleza compleja, que se desarrolla progresivamente Añón postula que se debe evolucionar a la prueba de la desventaja del grupo social que sufre la subordinación, con ello "[s]e apunta así hacia un abandono del término de comparación y la aplicación del test de la desventaja"28.

Para concluir este apartado de discriminación estructural, se observa que esta se encuentra fuertemente relacionada con la igualdad, en específico con la igualdad material, en razón de la cual los Estados deben de tomar medidas tendientes a la equiparación de condiciones de aquellas personas pertenecientes a un grupo desventajado, ello con el fin de generar las condiciones necesarias para asegurar los derechos de todos aquellos que habiten su territorio teniendo en especial consideración las desventajas que le aquejan y tomando las medidas necesarias para eliminar aquellos factores de desventaja o subordinación a que se ven enfrentados estos grupos. Puesto que esta categorización de discriminación "hunde sus raíces en la presencia de estereotipos sociales que asignan a las personas discriminadas roles de subordinación" 29.

\footnotetext{
25 Torbisco (2005), p. 47.

${ }^{26}$ Saba (2016), p.46.

27 García (2011), p. 166.

${ }^{28}$ Añón (2016), p. 150.

${ }^{29}$ Barranco (2014), p. 30.
} 
La relación entre la discriminación estructural y la discriminación interseccional radica en las fuentes de la discriminación interseccional, aquellas causales que confluyen son, en general, materias de estudio de la denominada discriminación estructural, como señala Young comparando a estas causales de discriminación con alambres “[c]onsiderados uno por uno, ningún alambre es capaz de evitar que un pájaro vuele. Es la relación conjunta de los alambres lo que impide el vuelo"30.

\section{Interseccionalidad y discriminación interseccional}

\subsection{CONCEPTO Y CARACTERÍSTICAS DE LA INTERSECCIONALIDAD}

En palabras de Platero, "[1]a "interseccionalidad" puede ser definida como la variedad de fuentes estructurales de desigualdad que mantienen relaciones recíprocas, subrayando que el género, la etnia, la clase o la orientación sexual, por ejemplo, son categorías sociales construidas y que están interrelacionadas"31. Un ejemplo de lo anterior, entenderíamos que estamos frente a una interseccionalidad de fuentes estructurales de desigualdad en el caso de una mujer, inmigrante, en situación de pobreza.

Si bien se trata de un fenómeno estudiado principalmente en el campo de la sociología, área desde la cual ha sido desarrollado, su estudio dentro del campo de las ciencias jurídicas comienza a partir de la publicación de Kimberlee Crenshaw, quien a través del análisis de sentencias emitidas por tribunales estadounidenses y los escritos emanados del colectivo Combahee River, sentó el concepto de interseccionalidad, la cual se define como “[...] los complejos, irreductibles, variados y variables efectos que resultan cuando múltiples ejes de diferencia -económica, política, cultural, psíquica, subjetiva y experiencial- se intersecan en contextos históricos específicos"32. En el caso particular de las mujeres de raza negra, en las cuales basa gran parte de sus estudios resume su postura diciendo que las mujeres negras pueden experimentar la discriminación en modos que pueden resultar tanto similares como diferentes a los experimentados por mujeres blancas y hombres negros. A menudo, señala, experimentan una doble-discriminación, entendiendo por tal a "los efectos combinados de prácticas que discriminan con base en la raza y con base en el sexo" 33. Por ejemplo, en la Convención Belém do Pará se reconoce la interseccionalidad a la que se ven enfrentadas las mujeres al señalar en

\footnotetext{
${ }^{30}$ Young (2011), p. 71.

${ }^{31}$ Platero (2012), p. 3.

32 Brah (2013), p. 1.

${ }^{33}$ Barrère y Morondo (2011), p. 30.
} 
su artículo 9, que, “[p]ara la adopción de las medidas a que se refiere este capítulo, los Estados Parte tendrán especialmente en cuenta la situación de vulnerabilidad a la violencia que pueda sufrir la mujer en razón, entre otras, de su raza o de su condición étnica, de migrante, refugiada o desplazada" 34 .

El fenómeno de la interseccionalidad posee una naturaleza compleja, debido a que no solo se trata de un factor que crea desigualdad en un aspecto negativo, sino que, además, ayuda a conformar la identidad misma del sujeto, tal como señala Julia S. Jordan-Zachery para quien "resulta inconcebible que su identidad sea desmembrada en base a que es una mujer por una parte y una persona de color por otra, ello debido a que considera que su femineidad se encuentra ligada a su raza"35. Este carácter forjador de la identidad de los sujetos en quienes concurren estas causales de discriminación produce que estas personas sean discriminadas por la sociedad en su conjunto, incluso en aquellos colectivos donde se supone sus demandas reciben acogida dejándoles en una situación extrema y agravada de vulnerabilidad y desprotección.

\subsection{DISCRIMINACIÓN INTERSECCIONAL: CONCEPTO Y CARACTERÍSTICAS}

Cuando hablamos de discriminación generalmente entendemos que esta

[...] debe entenderse referid[a] a toda distinción, exclusión, restricción o preferencia que se basen en determinados motivos, como la raza, el color, el sexo, el idioma, la religión, la opinión política o de otra índole, el origen nacional o social, la posición económica, el nacimiento o cualquier otra condición social, y que tengan por objeto o por resultado anular o menoscabar el reconocimiento, goce o ejercicio, en condiciones de igualdad, de los derechos humanos y libertades fundamentales de todas las personas ${ }^{36}$.

Una visión más contemporánea del principio de no discriminación considera la realidad de los grupos vulnerables y la subordinación que sufren. “Esta concepción condena las prácticas que tienen el efecto de crear o perpetuar en nuestra sociedad una posición subordinada para ciertos grupos desaventajados [...]"37. Avance que abrió la puerta al estudio de las denominadas discriminaciones compuestas.

Dentro de dichas asociaciones entre causales de discriminación se encuentra la discriminación interseccional, la cual trae aparejada “[...] una consecuencia concreta y específica

\footnotetext{
34 OEA. "Convención de Belém do Pará", artículo 9.

35 Jordan-Zachery (2007), p. 261 T. del A.

${ }^{36}$ Comité de Derechos Humanos. Observación General № 18. No discriminación, 1989, párrafo 7.

${ }^{37}$ Comisión Interamericana Derechos Humanos, Acceso a la justicia para las mujeres víctimas de violencia en las Américas, 20 de enero de 2007, párrafo 75.
} 
que, aunque derivada de la conjunción de los dos factores, sea propia e incluso diversa, de la que pudo haberse producido, de tenerlos en cuenta por separado" 38.

El origen de la denominación para este especial y agravado tipo de discriminación se encuentra en Estados Unidos, donde Kimberlé Crenshaw lo desarrolló basándose en la situación de mujeres afroamericanas quienes sufrían de trato discriminatorio incluso dentro los grupos donde deberían sentirse acogidas, por ejemplo, no encontraban solución a denuncias de violencia de género por parte del movimiento por los derechos civiles, nacionales y anticoloniales, porque en primer lugar este se encontraba dirigido a la experiencia de los hombres de color, y en segundo lugar se les solicitaba no denunciar episodios de violencia de género para no aumentar los estereotipos negativos relacionados con los hombres afrodescendientes, invisibilizando con dicho actuar las demandas de las mujeres negras que sufrían violencia en sus hogares.

Tampoco encontraban acogida en las políticas del movimiento feminista, donde sus requerimientos específicos relacionados a su raza eran acallados por el bien del colectivo. Discriminación similar sufrían las mujeres chicanas, o mujeres que por una u otra razón eran consideradas como las otras dentro del movimiento feminista, y por tanto sus demandas eran ignoradas. Como consecuencia de ello, las mujeres pertenecientes a una etnia o raza diversa de la blanca "han compartido una conciencia de cómo su identidad sexual combinada con su identidad racial hacía[n] que toda su situación vital y el foco de sus luchas políticas fueran únicos"39.

La relación que se da entre las diversas vulnerabilidades presentes posee un grado extremadamente intrincado con el "ser" del sujeto en que concurre porque si bien las vulnerabilidades múltiples, al igual que aquellas singulares, forjan su identidad; a diferencia de estas, no les permite integrarse a un grupo humano, al menos no en forma completa, porque sus demandas particulares no son las mismas de la generalidad de cada colectivo por lo que se ven en una posición de vulnerabilidad que alcanza tal grado que, incluso donde debiesen encontrar a lo menos empatía, encuentran invisibilización e incluso exclusión. Situación que ocurre incluso en la actualidad donde se puede observar una ola negacionista de la existencia de los derechos de las personas transexuales, particularmente en el caso de las mujeres, cuya inclusión en el

${ }^{38}$ Catalá (2010), pp. 10-11.

${ }^{39}$ Combahee River Collective (1977), p. 76. 
movimiento feminista no ha estado exento de polémica, no siendo generalizada su aceptación dentro de dicho movimiento.

Al igual que cualquier acto discriminatorio, la discriminación interseccional se produce en un contexto histórico y cultural determinado, donde sus diversas manifestaciones merman el ejercicio de derechos fundamentales en el día a día de los sujetos en quienes concurren y les hace ser en muchas oportunidades los excluidos dentro de los excluidos.

En este punto cabe mencionar que "[n]aturalmente, son factibles discriminaciones múltiples conjugando más de dos causas, y conjugando estas causas sin intervención del sexo/género"40. Sin perjuicio de ello "la metodología usada por el colectivo feminista pareciera ser particularmente adecuada para el estudio de otras relaciones estructurales (ideológicas o sociales) que crean desigualdad en las personas" 41 .

La situación socioeconómica siendo una causal de discriminación por si misma hace aún más vulnerable la condición de aquellos sujetos que no poseen los medios para proveerse por sí mismos de las distintas prestaciones que dependen exclusivamente de las políticas estatales donde pueden verse enfrentados a la denominada "interseccionalidad política”, la cual "[...]se refiere a la relevancia que las intersecciones entre desigualdades tienen para las estrategias políticas de instituciones y movimientos sociales, en el sentido de que las estrategias políticas que se dirigen a una desigualdad concreta por lo general no son neutrales hacia las demás desigualdades"42. Viéndose en un estado de desprotección que puede tener consecuencias tanto relacionadas con el acceso a oportunidades, prestaciones sociales, entre muchos otros.

El analizar la discriminación desde la perspectiva interseccional “obliga a una revisión del Derecho antidiscriminatorio clásico basado en la yuxtaposición de los factores de discriminación"43. Análisis que revela“[...] que las desigualdades son producidas por las interacciones entre los sistemas de subordinación de género, orientación sexual, etnia, religión, origen nacional, discapacidad y situación socio-económica" 44 y, debido a la íntima relación del principio antidiscriminatorio con la igualdad, en particular con la igualdad material y las

\footnotetext{
${ }^{40}$ Lousada (2017), p. 2.

41 García (2007), p. 234. T del A.

${ }^{42}$ Lombardo y Verloo (2010), p. 12.

${ }^{43}$ Barrère (2010), p. 251.

${ }^{44}$ La Barbera (2016), p. 106.
} 
medidas de discriminación positiva que se toman en favor de aquellos sujetos estructuralmente discriminados es que estas “[...] necesitan afrontar el reto de la interseccionalidad" 45 .

La discriminación interseccional explica como las múltiples identidades de un sujeto pueden ser la causa de discriminación en tal forma que las causales no pueden ser consideradas en forma separada. Fredman \& Szyszak señalan emulando a Crenshaw que los efectos acumulativos de la discriminación basada en raza y sexo no es solo aditiva. Las mujeres negras experimentan problemas que no comparten ni las mujeres blancas ni los hombres negros. Y entregan un ejemplo para ilustrar la situación "por ejemplo, a diferencia de las mujeres blancas, las mujeres negras ven el aborto como un mecanismo de coerción, y no como un asunto de autonomía"46.

No hay acuerdo en la doctrina sobre si se debe equiparar el término discriminación interseccional con la denominada discriminación múltiple, debate no observado jurisprudencialmente donde se usan indistintamente ambos términos. Sin embargo, a nivel doctrinal hay quienes las diferencian basándose en la simultaneidad, en la concurrencia de aquellos criterios de discriminación aplicables a la persona, siendo la discriminación múltiple aquella en que una persona sufre discriminación por más de un factor en diferentes momentos de su vida. Mientras que la discriminación interseccional solo ocurriría cuando los diversos criterios de discriminación que puede sufrir una persona confluyen al mismo tiempo. Con el fin de ejemplificar lo anterior, estaríamos hablando de discriminación múltiple en el caso de una mujer de ascendencia mapuche, quien concurre a un centro de salud a recibir atención médica y es discriminada debido a su sexo. En otras oportunidades y contextos de su vida esta misma persona ha sido discriminada siendo el factor determinante para esta su ascendencia mapuche. En cambio, estaríamos hablando de discriminación interseccional si la misma persona concurre con ropa tradicional de su etnia al mismo centro asistencial y es discriminada al momento de recibir atención de salud no solo debido a su sexo, sino que además por su ascendencia étnica y todos los elementos externos que ella conlleva ${ }^{47}$.

Una de las posiciones es la mantenida por Makkonen, quien realiza una clasificación de diversos tipos de discriminaciones en que concurre más de una causal, en un primer ejemplo concurren en la persona diversas causales de discriminación, pero aquellas oportunidades en

\footnotetext{
${ }^{45}$ Barrère (2010), p. 251.

${ }^{46}$ Fredman y Szyszak (1993), p. 221.

${ }^{47}$ V.g. vestimenta, accesorios, etc.
} 
que el sujeto sufre de discriminación esta se basa en una causal por vez, en este caso Makkonen le denomina discriminación múltiple.

En Segundo lugar, una situación en que las causales de discriminación se suman entre si creando una situación de discriminación compuesta. Tercero una situación que involucra discriminación basada en diversas causales que operan e interactúan entre si al mismo tiempo y que produce tipos muy específicos de discriminación. Esto se denomina discriminación interseccional $[\ldots]^{48}$.

Sin embargo, coincidimos con autores como Rey Martínez, quien discrepa de Makkonen al señalar que

"[l]o que Makkonen llama discriminaciones «múltiples» no lo son en sentido estricto y las discriminaciones «combinadas» o son lo mismo que las discriminaciones «interseccionales» o, a lo sumo, una especie de su género. Esta taxonomía induce a la confusión conceptual si no se tiene en cuenta que la única expresión que capta con precisión el fenómeno en examen es la discriminación que Makkonen llama «interseccional»"49.

Este autor, sin embargo, prefiere hacer uso del término múltiple para referirse a esta discriminación en particular, ello por motivos lingüísticos. Consideramos más adecuado el término discriminación interseccional porque la palabra intersección si es vista desde diversas áreas del quehacer humano, se refiere a un punto de encuentro, de cruce que sentimos se acerca más a las relaciones que se generan entre las diversas causales al momento de producirse un acto discriminatorio motivado por ellas.

Actualmente, "[t]anto en el Derecho internacional como en el de los Estados, la prohibición de discriminación se aborda invariablemente a partir del análisis de un solo factor de discriminación y rara vez combinando varios. Se suelen tratar como rectas paralelas que siempre guardan la misma distancia y nunca se cortan"50. En cambio, “cuando una persona experimenta discriminación aditiva es discriminada por dos o más causales de discriminación al mismo tiempo"51. Sufriendo el sujeto por ello "[d]esventajas en un área de la vida comúnmente [las cuales] refuerzan las desventajas en otras áreas de esta. Enfocarse en un solo evento es insuficiente para remediar las experiencias de una persona en particular"52.

El concepto de discriminación múltiple ha sido reconocido expresamente en la Conferencia de Naciones Unidas contra el Racismo, la Discriminación Racial, la Xenofobia y la Intolerancia,

\footnotetext{
${ }^{48}$ Makkonen (2002), p.10 T. del A.

${ }^{49}$ Rey (2008), p. 267.

${ }^{50}$ Rey (2008), p. 254.

${ }^{51}$ Hannett (2003), p. 68 T. del A.

52 Makkonen (2002), p. 5 T. del A.
} 
celebrado en Durban (Sudáfrica) en 2001 donde se señaló en relación con la situación de las mujeres que los Estados “[...]deberían aplicar una perspectiva de género que reconozca las múltiples formas de discriminación que pueden afectar a las mujeres”53, de igual forma en dicha conferencia se señala en relación con las personas afrodescendientes que los Estados deben aplicar “[...] políticas y medidas encaminadas a prevenir y eliminar toda discriminación basada en la religión y las creencias que, combinada con ciertas otras formas de discriminación, constituye una forma de discriminación múltiple"54.

Fernando Rey señala que "evidentemente, no es nueva la idea de que algunas víctimas de discriminación lo son por varios rasgos asociados a estereotipos negativos hondamente arraigados en la sociedad, lo que, por un lado, amplifica la gravedad de la herida de su dignidad y, por otro, transforma de alguna manera el tipo de lesión"55. “Tanto en el Derecho internacional como en el de los Estados, la prohibición de discriminación se aborda invariablemente a partir del análisis de un solo factor de discriminación [...] y rara vez combinando varios. Se suelen tratar como rectas paralelas que siempre guardan la misma distancia y nunca se cortan. [...] Este enfoque está cambiando"56.

\subsection{RECONOCIMIENTO JURISPRUDENCIAL}

El enfoque monocausal acostumbrado en el caso de la discriminación de personas en que confluyen diversas causales de discriminación ha evolucionado con el paso de los años, siendo acogido por el Tribunal Europeo de Derechos Humanos (TEDH) en el año 2012, mientras que la Corte IDH lo hizo en el año 2015.

\subsubsection{RECONOCIMIENTO POR PARTE DE LOS SISTEMAS REGIONALES}

Una sentencia ya emblemática del Tribunal Europeo de Derechos humanos se da en el caso B.S vs. España, primera sentencia en que se reconoce la existencia de la discriminación interseccional.

Este caso se refiere a una mujer afrodescendiente, dedicada a la prostitución, quien es sometida a controles de identidad por parte de la policía en forma insistente, controles que fueron realizados mientras los agentes proferían insultos racistas e incluso lesionándola en

\footnotetext{
${ }^{53}$ Declaración de Durban 2001 preámbulo.

${ }^{54}$ Declaración de Durban 2001. Las víctimas del racismo, la discriminación racial, la xenofobia y las formas conexas de intolerancia, № 14 .

${ }^{55}$ Rey (2008), p. 254.

${ }^{56}$ Rey (2008), p. 254.
} 
diversas oportunidades. Cuando esta persona intentó recurrir a las autoridades tanto administrativas como jurisdiccionales no obtuvo respuesta alguna o se le imponían trabas que hacían imposible verificar la identidad de los autores de sus lesiones, por lo que procesar a los responsables de estas agresiones fue imposible.

El Tribunal Europeo falló que

[a] la luz de los elementos de prueba proporcionados en este caso, el Tribunal estima que las decisiones dictadas por los Órganos Jurisdiccionales internos no tuvieron en cuenta la vulnerabilidad específica de la demandante, inherente a su condición de mujer africana ejerciendo la prostitución. Las Autoridades faltaron así a la obligación que les incumbía, en virtud del artículo 14 del Convenio combinado con el artículo 3, de adoptar todas las medidas posibles para ver si una actitud discriminatoria hubiera podido, o no, desempeñar algún papel en los sucesos ${ }^{57}$.

En este caso el acto discriminatorio fue cometido en un contexto donde la prostitución no se encontraba penada por la ley, en un sector donde normalmente se ejerce dicha actividad, sin embargo esta mujer fue discriminada, insultada y golpeada en un lugar donde otras mujeres dedicadas a la misma actividad podían realizarla sin problemas. Dentro de los malos tratos proferidos por los agentes policiales abundaron insultos tanto de carácter racista como relacionados con su actividad y fue instada en forma violenta a abandonar el lugar donde se encontraba trabajando, incurriendo claramente en un acto discriminatorio donde la motivación fue tanto racial, posiblemente por su condición migrante relacionada con su raza, y su ocupación. Esta confluencia de diversas causales de discriminación finalmente causaron que esta mujer en primer lugar fuese discriminada y lesionada en forma física; en segundo lugar que los intentos por identificar a los agentes involucrados en su caso fuesen infructuosos y finalmente la inacción del poder judicial que causó finalmente que la víctima acabase en un estado de indefensión por parte del estado español, vulnerando con ello la garantía de no recibir tratos inhumanos o degradantes y su derecho a no ser discriminada.

De la misma manera, el Tribunal Europeo emitió la sentencia del Asunto Carvalho Pinto de Sousa Morais vs. Portugal de 2017. En dicho caso el Tribunal se pronunció sobre el caso de una mujer, quien luego de una negligencia médica comenzó a sufrir un intenso dolor, además perdió la sensibilidad de su vagina. Negligencia que le impidió realizar su vida en forma normal, lo que finalmente derivó en un aislamiento social y depresión que se ha mantenido en el tiempo.

${ }^{57}$ Tribunal Europeo de Derechos Humanos, Asunto B.S contra España, de 24 de julio 2012, párrafo 71. 
En este caso la infracción se cometió por parte del Tribunal Superior Administrativo, ente que, al momento de fijar la indemnización procedente en ese caso, en específico a aquella relacionada con la contratación de una asistenta para la realización de las labores domésticas que la demandante ya no podía realizar por sí misma la disminuyó principalmente debido a que los hijos de la demandante eran mayores de edad y que sus obligaciones se veían reducidas a atender a su marido, lo que, a juicio del tribunal, no justificaba incluir en la indemnización los gastos asociados a la contratación de una asistenta a tiempo completo. Además, se consideró como factor al momento de fijar el monto de la indemnización que la demandante para el momento de la ocurrencia de los hechos ya tenía 50 años, por lo que la sexualidad no era tan importante como en la juventud.

El Tribunal concluyó que el Estado portugués vulneró la prohibición de la discriminación en este caso (en relación con el derecho al respeto de la vida privada y familiar) y para determinarlo indicó que la edad y el sexo de la mujer parecen haber sido factores decisivos en la decisión final de este caso, introduciendo con dicha acción una diferencia de trato basada en un más criterio sospechoso de discriminación. En este caso es observable el efecto negativo que pueden tener los estereotipos aplicados por parte de las autoridades de justicia, en un primer término se aplica un estereotipo sexista relacionado con el "deber" de la mujer de atender a su marido y sus hijos y, estos al crecer "liberan" a su madre de sus obligaciones por lo que solo se requeriría una asistenta de medio tiempo para velar por las necesidades del marido. En un segundo lugar se aplican igualmente estereotipos relacionados con la edad y el ejercicio de la sexualidad considerando que una persona de su edad no merecía una compensación por perder la posibilidad de ejercer su sexualidad en forma normal puesto que a la edad de la recurrente esta no era relevante, sentando incluso la duda si dicha falta de relevancia decía relación con su actividad sexual o con su capacidad reproductiva, ambos en igual caso basados en estereotipos de género y etarios.

Como se mencionó anteriormente la Corte Interamericana de Derechos Humanos ha reconocido de igual forma la existencia de la discriminación interseccional. En el caso Gonzáles Lluy vs. Ecuador del año 2015 se utilizó por primera vez dicho término por parte de la Corte IDH. En dicha sentencia la Corte conoce de la situación de Talia González, una joven ecuatoriana proveniente de una familia de escasos recursos quien fue contagiada a corta edad con el virus del VIH al momento de realizársele una transfusión de sangre. 
La joven fue discriminada en múltiples ocasiones debido a su condición, tanto en el plano educacional como en la prestación de servicios de salud, entre otros. Además, dicha discriminación se extendió a los miembros de su familia próxima, madre y hermano, quienes vieron mermadas sus posibilidades habitacionales, laborales y académicas debido a la condición de Talia. En este caso,

[1]a Corte nota que en el caso de Talía confluyeron en forma interseccional múltiples factores de vulnerabilidad y riesgo de discriminación asociados a su condición de niña, mujer, persona en situación de pobreza y persona con VIH. La discriminación que vivió Talía no sólo fue ocasionada por múltiples factores, sino que derivó en una forma específica de discriminación que resultó de la intersección de dichos factores, es decir, si alguno de dichos factores no hubiese existido, la discriminación habría tenido una naturaleza diferente [...]. En suma, el caso de Talía ilustra que la estigmatización relacionada con el VIH no impacta en forma homogénea a todas las personas y que resultan más graves los impactos en los grupos que de por sí son marginados ${ }^{58}$.

Además, dicha discriminación se vio "reforzada en el presente caso debido a los factores de múltiple vulnerabilidad en que se encontraba la [presunta] víctima en su condición de niña portadora de VIH de muy escasos recursos"59.

Por su parte la Comisión Interamericana de Derechos Humanos (CIDH) ha señalado, en el caso de la violencia sufrida por mujeres indígenas en territorio canadiense que

[...] [1]a pobreza, la vivienda inadecuada, y la relegación económica y social, entre otros factores, contribuyen a su mayor vulnerabilidad a la violencia. Adicionalmente, las actitudes prevalentes de discriminación - principalmente relacionadas con el género y la raza-y los estereotipos arraigados a los que se han visto sujetas, exacerban su vulnerabilidad ${ }^{60}$.

Tanto en el caso Gonzales Lluy como por parte de la CIDH se tiene en consideración la vulnerabilidad económica en que se encuentran las víctimas. Tal como se señaló con anterioridad la pobreza juega un importante rol en las situaciones de discriminación interseccional puesto que esta exacerba las situaciones de vulnerabilidad y hace que los sujetos necesiten de una efectiva acción estatal para poder acceder a la vida en sociedad en condiciones de igualdad con sus conciudadanos, las cuales deben, para ser eficaces, tener necesariamente en consideración los diversos factores que puedan influir en forma negativa en las interacciones sociales y con la institucionalidad y las posibles interrelaciones que puedan darse entre estos para enfocar su actuar en una forma general y particular accediendo con ello a la igualdad material entre sus habitantes.

${ }^{58}$ Corte Interamericana Derechos Humanos, Gonzáles Lluy y otros vs. Ecuador, de 1 septiembre 2015, párrafo 230.

${ }^{59}$ Corte Interamericana Derechos Humanos, Gonzales Lluy y otros vs. Ecuador, de 1 septiembre 2015, párrafo 230.

${ }^{60}$ Comisión Interamericana Derechos Humanos, Mujeres indígenas desaparecidas y asesinadas en Columbia Británica, Canadá. 
En el Caso trabajadores de la Hacienda Brasil Verde vs. Brasil se observa como la pobreza incide directamente en las vulneraciones que pueden sufrir los sujetos, sea ello por parte de particulares como por parte de las autoridades estatales. En este caso se relata el caso de 85 personas quienes habían sido reclutados en sus regiones de origen y trasladados a la Hacienda Brasil, donde se les informaba que por gastos de transporte debían trabajar para la hacienda, posteriormente aumentaban la deuda con aquellos insumos que los trabajadores requerían para su manutención, los cuales compraban a precios afectos a inflación exagerada lo que junto con aumentar su deuda aumentaba la esclavitud de hecho en que se encontraban porque al verse imposibilitados se realizar el "pago" de las deudas que contraían no dejaban nunca de prestar funciones en la hacienda.

Estos reclutadores de esclavos normalmente buscaban entre sus víctimas a personas pobres, con altos índices de analfabetismo "[l]os trabajadores, en su mayoría hombres pobres afrodescendientes o morenos (mulatos) entre 18 y 40 años, son reclutados en sus estados de origen por los "gatos" [reclutadores] para trabajar en Estados alejados, con la promesa de salarios atractivos"61. Los trabajadores además de ser llevados en forma engañosa a la hacienda eran retenidos contra su voluntad por parte de guardias armados y amenazas. El Estado fue condenado en definitiva por no tomar medidas en contra de dichas prácticas esclavistas, prácticas que estaban en su conocimiento y de igual forma por no dirigir investigaciones eficaces en los casos de desapariciones. El juez Ferrer Mac-Gregor en voto razonado señala

[p]ara los fines del derecho antidiscriminatorio, la posición económica alude a situaciones estructurales de negación, por diversas circunstancias, a un sector de la población, de necesidades generales de vida digna y autónoma. Debe entenderse, pues, dentro del conjunto de situaciones que impiden que una persona desarrolle una vida digna, como el acceso y disfrute a los servicios sociales más básicos ${ }^{62}$.

En junio del año 2015 la Asamblea General de la OEA adopta la Convención Interamericana sobre la Protección de los Derechos Humanos de las Personas Mayores, en la cual se define la discriminación múltiple como “[c]ualquier distinción, exclusión o restricción hacia la persona mayor fundada en dos o más factores de discriminación"63. Por su parte la Convención Interamericana Contra Toda Forma de Discriminación e Intolerancia la define como

cualquier preferencia, distinción, exclusión o restricción basada, de forma concomitante, en dos o más de los motivos mencionados en el artículo 1.1 u otros reconocidos en instrumentos

\footnotetext{
${ }^{61}$ Corte Interamericana Derechos Humanos, caso Trabajadores Hacienda Brasil Verde vs. Brasil, de 20 octubre de 2016, párrafo 81.

${ }^{62}$ Corte Interamericana Derechos Humanos, caso Trabajadores Hacienda Brasil Verde vs. Brasil, de 20 octubre de 2016, voto razonado, párrafo 54.

${ }^{63}$ OEA Convención Interamericana sobre la Protección de los Derechos Humanos de las Personas Mayores art. 2.
} 
internacionales que tenga por objetivo o efecto anular o limitar, el reconocimiento, goce o ejercicio, en condiciones de igualdad, de uno o más derechos humanos y libertades fundamentales consagrados en los instrumentos internacionales aplicables a los Estados Partes, en cualquier ámbito de la vida pública o privada ${ }^{64}$.

En el caso I.V v. Bolivia la Corte reconoce que la concurrencia de diversos factores que causan discriminación puede terminar con la afectación de otros Derechos Humanos, al señalar que "el presente caso es un ejemplo de las múltiples formas de discriminación que afectan el goce y ejercicio de derechos humanos por parte de algunos grupos de mujeres, como I.V., en base a la intersección de diversos factores como su sexo, condición de migrantes y posición económica”65. Intersección de vulnerabilidades que eventualmente causó que esa mujer fuese esterilizada sin su consentimiento. "La Corte ha reconocido que ciertos grupos de mujeres padecen discriminación a lo largo de su vida con base en más de un factor combinado con su sexo, lo que aumenta su riesgo de sufrir actos de violencia y otras violaciones de sus derechos humanos" 66 .

En relación con las consecuencias gravosas que produce la ocurrencia de una discriminación basada en diversos factores que confluyen conjuntamente la Corte IDH señala que

[...]la interseccionalidad en el presente caso es fundamental para entender la injusticia específica de lo ocurrido a Talía y a la familia Lluy, la cual solo puede entenderse en el marco de la convergencia de las diversas discriminaciones ocurridas. La interseccionalidad constituye un daño distinto y único, diferente a las discriminaciones valoradas por separado. Ninguna de las discriminaciones valoradas en forma aislada explicaría la particularidad y especificidad del daño sufrido en la experiencia interseccional. En el futuro la Corte IDH podrá ir precisando los alcances de este enfoque, lo cual contribuirá a redimensionar el principio de no discriminación en cierto tipo de $\operatorname{casos}^{67}$.

Si bien se trata de un concepto relativamente reciente tanto en la jurisprudencia del TEDH como de la Corte IDH, podemos concluir que este se encuentra ya sentado en jurisprudencia internacional con lo que es esperable que se continúen utilizando los argumentos que han dado origen a dichos pronunciamientos y que la consideración de este tipo de discriminación aumente, tanto a nivel jurisprudencial de los Estados parte de los diversos tratados sobre DDHH de que conocen estos tribunales, como de las medidas que esos mismos Estados deben tomar para erradicar tanto la discriminación estructural como interseccional que sufren estos grupos. Como se mencionó anteriormente, ello se logra por medio de políticas sociales tendientes a la equiparación de condiciones sociales entre los individuos pertenecientes a un grupo vulnerable con el resto de los ciudadanos $\mathrm{y}$, al momento de ponerlas en práctica tener en especial

${ }^{64}$ OEA Convención Interamericana Contra Toda Forma de Discriminación e Intolerancia art. 2.

65 Corte Interamericana Derechos Humanos, caso I.V. vs. Bolivia, de 30 noviembre 2016, párrafo 329.

${ }^{66}$ Corte Interamericana Derechos Humanos, caso I.V. vs. Bolivia, de 30 de noviembre 2016, párrafo 247.

${ }^{67}$ Corte Interamericana Derechos Humanos, caso Gonzales Lluy vs. Ecuador, de 1 septiembre 2015, párrafo 12. 
consideración a aquellos individuos en quienes concurre otra u otras causales de discriminación con el fin de no crear políticas que acaben por excluir a personas de políticas en apariencia generales a las demandas de un colectivo.

\subsubsection{DiSCRIMINACIÓN INTERSECCIONAL EN LA JURISPRUDENCIA CORTE SUPREMA}

Acercando el tema de la interseccionalidad a la jurisprudencia nacional y específicamente aquella emanada de la Corte Suprema es que recordamos lo señalado en el fallo Almonacid Arellano vs. Chile, en relación con el control de convencionalidad, donde se señala que, "en otras palabras, el Poder Judicial debe ejercer una especie de "control de convencionalidad" [...] En esta tarea, el Poder Judicial debe tener en cuenta no solamente el tratado, sino también la interpretación que del mismo ha hecho la Corte Interamericana, intérprete última de la Convención Americana"68. Dicho control de convencionalidad

[...]debe ser desarrollado por los jueces nacionales implica internalizar en su actividad jurisdiccional que son jueces interamericanos en el plano nacional, debiendo siempre garantizar los atributos de los derechos contenidos en la CADH, impidiendo que éstos sean afectados por normas jurídicas de derecho interno o conductas y actos de agentes del Estado que desconozcan los estándares mínimos determinados convencionalmente ${ }^{69}$.

Considerando que desde el 2015 la Corte Interamericana sobre Derechos Humanos reconoce la interseccionalidad en la discriminación y que, en general su incorporación en tratados que componen el ordenamiento interamericano ha sido amplia, también es reciente, y trae como consecuencia que el uso de dicho término por parte de la Corte Suprema de nuestro país sea más bien cauto, siendo usado pocas veces en forma directa o literal.

Si bien nuestro país cuenta con una normativa especial en materias de discriminación contenida en la ley 20.609 denominada comúnmente como "ley Zamudio" aquellos fallos no forman parte de la presente investigación principalmente porque dichas acciones no llegan en instancia ordinaria a la Corte Suprema, y siendo esta la que mantiene un dialogo jurisprudencial más fluido con la Corte IDH en nuestro país es que se estimó más adecuada la jurisprudencia emanada de nuestro tribunal superior para evaluar el uso de criterios de la Corte IDH.

La única resolución Corte Suprema donde se acepta la existencia de la discriminación interseccional en forma explícita recayó en un recurso de amparo, el cual fue presentado a favor de una mujer que se encontraba privada de libertad, embarazada y perteneciente a la etnia

${ }^{68}$ Corte Interamericana Derechos Humanos, caso Almonacid Arellano y otros vs. Chile, de 26 de septiembre de 2006, párrafo 124.

${ }^{69}$ Nogueira (2012), p. 70. 
mapuche. L.C.L, la mujer amparada contaba con un embarazo de 32 semanas, en razón del cual el día 13 de octubre de 2016 fue derivada desde la enfermería del recinto penitenciario donde se encontraba cumpliendo condena, al Servicio de Urgencia del Hospital de Arauco, no siendo claras las circunstancias de este, pero según relata la amparada ella iba a bordo de un taxi particular, esposada y acompañada en dicho vehículo por personal de Gendarmería y era escoltada por un vehículo institucional y dos motoristas de Carabineros.

Una vez en el centro médico de urgencias se le diagnostica "preeclampsia" por lo que es trasladada al Hospital Regional de Concepción, en dicho traslado L.C.L fue engrilletada por el pie izquierdo a la camilla de la ambulancia, los cuales fueron retirados posteriormente y solo por la intervención del personal médico, quienes lo solicitaron al momento de examinarla. Posteriormente es trasladada a la Clínica de la Mujer de la misma ciudad, donde finalmente son retirados, ya en forma definitiva, los grilletes que eran puestos nuevamente por personal de Gendarmería cuando terminaban de realizarse los controles médicos.

Finalmente la Corte se pronuncia a favor de la amparada, señalando

[q]ue, así las cosas, se estima que en el caso sub judice hay una situación paradigmática de interseccionalidad en la discriminación, [...] pues recibió un trato injusto, denigrante y vejatorio, dada su condición de mujer, gestante y parturienta, privada de libertad y perteneciente a la etnia mapuche, lo que en forma innecesaria puso en riesgo su salud y vida, así como la de su hijo, todo ello, en contravención a la normativa nacional e internacional vigente en la materia. Estas reglas, han advertido que la convergencia de múltiples formas de discriminación aumenta el riesgo de que algunas mujeres sean víctimas de discriminación compuesta $[\ldots]^{70}$.

Situación donde “[...] diversos factores de discriminación interactúan simultáneamente [...]. Este tipo de vulneración se caracteriza por lo siguiente: (i) Intervención de dos o más factores de vulnerabilidad; (ii) Que estos se presenten simultáneamente; y (iii) Que la interacción de aquellos genere una forma de discriminación especial que tiene un efecto propio o único" ${ }^{71}$. Es en base a estos aspectos que la Corte concluyó que se observa "una situación paradigmática de interseccionalidad en la discriminación, donde se observa una confluencia de factores entrecruzados de discriminación que se potencian e impactan negativamente en la amparada"72.

En este caso se observa en forma particularmente ejemplar cómo pueden influir la confluencia de causales de discriminación en formas y contextos particulares para generar vulneraciones a las garantías fundamentales. L.C.L era una mujer indígena, quien en ese en ese momento se encontraba privada de libertad y en estado de gravidez. Los funcionarios de

\footnotetext{
${ }^{70}$ Corte Suprema, Rol № 92795, de 1 de diciembre de 2016, considerando 16.

${ }^{71}$ Jopia y Labbé (2018), pp. 444-445.

${ }^{72}$ Corte Suprema, Rol № 92795-2016, de 1 de diciembre de 2016, considerando 16.
} 
gendarmería obviaron los deberes de protección y garantía que tienen sobre la población penal en general, la cual se ve reforzada en casos como el de la recurrente, considerando su estado y el avanzado estado de su embarazo. Sin embargo, al momento de realizar su traslado a un centro asistencial "sí tuvieron en consideración su condición de "comunera mapuche" para desplegar un amplio dispositivo de seguridad. Así, concurrían en la especie, dos categorías sospechosas de discriminación ${ }^{73}$.

Interesante es lo señalado en voto disidente en sentencia que se pronuncia con relación con un recurso de protección presentado por un adulto mayor a quien no se le permitía realizar una desafiliación de una AFP. En dicho pronunciamiento la Corte Suprema finalmente confirmó la sentencia original de la Corte de Apelaciones de Valparaíso, la cual rechazaba el recurso de protección presentado por don J. del C.P.P.

El ministro Sergio Muñoz votó por revocar dicha sentencia y acoger el recurso de Protección apelado, puesto que a su considerar, la nula respuesta por parte de la AFP al requerimiento de su afiliado vulnera a lo menos la igualdad ante la ley señalando que

[e]l mensaje que se entreg[a] por medio de las determinaciones de los tribunales, no solamente decide el caso particular, orienta en la construcción de la sociedad que queremos y este juez estima que el Estado no puede permitir estas conductas y esta forma de ejercer sus facultades por una entidad privada que ejerce funciones públicas, especialmente, en este caso, respecto de personas que se encuentran en una múltiple condición de vulnerabilidad, por ser pensionado del sistema de AFP, con una pensión asistencial mínima; su edad, que le hace difícil vincularse con los sistemas modernos de administración y gestión, como por su situación económica $[\ldots]^{74}$.

El impacto real de la pobreza en aquellos que ya poseen una característica que les hace vulnerables tiene un alcance que aún no ha sido completamente dimensionado y debe, necesariamente considerar la interacción de causales de discriminación, tal como hace el ministro en el presente caso.

En otra causa, donde se analizaba el caso de mujeres pertenecientes a Carabineros, a quienes les era negado el derecho a ascenso, manteniéndolas por una mayor cantidad de años de los requeridos para el siguiente escalafón. En dicha ocasión la acción fue rechaza con el voto disidente del ministro Muñoz, quien en su voto disidente se refirió a la situación enfrentada por las mujeres al integrarse al mercado de trabajo, señalando que

en esta tarea enfrentan múltiples discriminaciones, que están dadas no sólo por patrones estructurales y culturales, sino que también por rigideces jurídicas que la colocan en una situación de menoscabo [...] ante esta realidad el Estado no puede jugar un papel neutro, sino que debe implementar mecanismos y políticas que velen por la igualdad de género,

\footnotetext{
${ }^{73}$ Pérez (2017), p. 80.

${ }^{74}$ Corte Suprema Rol № 73935-2016, de 24 enero 2017, voto disidente.
} 
respetando así los compromisos que adquirió en el ámbito internacional a través de la suscripción de distintas Convenciones[... $]^{75}$.

Continua su razonamiento, señalando que el ingreso de las recurrentes a la institución “[...] se produce en condiciones similares a sus pares masculinos y, en consecuencia, encontrándose regidos por un único estatuto, resultaba obligatorio que éste fuera aplicado en condiciones igualitarias a la oficialidad de la institución, cuestión que en la especie no sucedió [...]"76. Actuación que vulneraba el derecho a la igualdad de las recurrentes tanto desde el punto de vista de su desarrollo profesional, como de aquel relacionado con las remuneraciones no percibidas por este actuar, perjuicio que incluso afecta las futuras prestaciones previsionales de las afectadas.

Como se mencionó la Corte Suprema ha hecho poco uso del término discriminación interseccional, aún en casos donde esta parece evidente como es en aquellos casos en que se observa discapacidad, minoría de edad y género, casos que representan “[...] el fiel reflejo de una discriminación interseccional [...] la Corte Suprema no utiliza esta elaboración interamericana, pudiendo haberlo hecho"77. Dicha posibilidad radica en el establecimiento de la existencia del control de convencionalidad difuso por parte de la Corte IDH a partir del fallo Almonacid Arellano vs. Chile y el pronunciamiento en materias de interseccionalidad en la discriminación a partir del año 2015, además del desarrollo cada más amplio del concepto por parte de la doctrina jurídica.

\section{Conclusiones}

El deber estatal de respetar y mantener la igualdad ante la ley ha ido en aumento, porque si bien en un comienzo se trataba de no realizar diferenciaciones odiosas en materia legislativa, paulatinamente, con el reconocimiento de la existencia de grupos que históricamente se han visto desventajados en el ejercicio de sus derechos, se ha aumentado el estándar exigible a los Estados que forman parte de nuestro sistema, pues la Corte IDH ha señalado que se aspira a lograr la igualdad material. Debido a ello se han dictado una serie de protocolos adicionales, que tienen por objeto la protección de estos grupos.

\footnotetext{
${ }^{75}$ Corte Suprema, Rol № 3750-2013, voto disidente, de 12 agosto 2013, considerando 7.

${ }^{76}$ Corte Suprema, Rol № 3750-2013, de 12 agosto 2013, voto disidente, considerando 8.

${ }^{77}$ Aguilar (2019), p. 80.
} 
Con el reconocimiento de la existencia de estos grupos marginados, y de la vulnerabilidad que les aqueja en forma estructural genera obligaciones adicionales para los estados del sistema interamericano, puesto que no solo deben compensar a la víctima de una discriminación estructural en el sentido material, sino que de igual forma debe tomar todas las medidas necesarias en el orden interno, sea legislativo o administrativo, para evitar la ocurrencia futura de hechos discriminatorios sobre un grupo particularmente oprimido.

La interseccionalidad, desde el punto de vista del sujeto, ayuda a explicar la especial relación que poseen aquellos pertenecientes a más de un grupo vulnerable, puesto que, la pertenencia a cada uno de estos grupos humanos ayuda a formar la forma en que ese sujeto se relacionara tanto con el colectivo como con aquellos que no forman parte de él, definiendo sus relaciones sociales en todo orden. Y, además, cada una de dichas vulnerabilidades ayuda a generar la identidad misma de la persona, como un núcleo indivisible. Razón por la que las mujeres de raza negra no veían reflejadas sus demandas en el colectivo feminista, puesto que este se encontraba enfocado desde la perspectiva de una mujer blanca, invisibilizando por completo aquellas problemáticas propias de su condición de persona de raza negra y mujer, intersección de características que, tal como se señaló anteriormente, condiciona el modo en que la persona se desenvuelve.

La interseccionalidad, vista desde el punto de vista de la eliminación de la opresión de aquellos sujetos a ella, contribuye a enfocar las políticas públicas de un modo adecuado, analizando las necesidades y requerimientos de cada sujeto. Acercándose más con ello a la anhelada igualdad material.

La discriminación interseccional por su parte, si bien se trata de un concepto no nuevo para el campo de las ciencias jurídicas, si es reciente en cuanto a su aplicación por parte de tribunales internacionales, por lo que es esperable que tanto el sistema europeo como americano continúen con el desarrollo de este concepto, y las especiales obligaciones que conllevan a los Estados parte de sus respectivas jurisdicciones.

Si observamos la relación temporal entre las sentencias de los diversos tribunales analizados, notamos que la Corte Suprema comienza sus acercamientos al concepto de discriminación interseccional en forma coetánea al primer pronunciamiento en el sistema internacional de Derechos Humanos. Por otra parte, la jurisprudencia de la Corte Suprema, si bien reconoce la discriminación interseccional en uno de sus pronunciamientos, no lo hace 
amparándose en los criterios esgrimidos por la Corte IDH ni por el TEDH, al menos no en forma explícita, por lo que se trataría de un criterio propio de la jurisprudencia nacional en esta materia.

Finalmente, creemos que es extremadamente relevante el estudio de la pobreza de una forma más completa, donde se considere las consecuencias gravosas a la dignidad de la persona tanto desde el punto de vista como causal de discriminación presente y a la vez como potenciador de vulnerabilidad en aquellos casos en que existe otra causal de discriminación estructural.

\section{Bibliografía citada}

Abramovich, Víctor (2009): “De las violaciones masivas a los patrones estructurales: nuevos enfoques y clásicas tensiones en el sistema interamericano de Derechos Humanos", en SUR (Vol. 6, № 11), pp. 7- 39.

Aguilar Cavallo, Gonzalo (2019): "El control de convencionalidad y la prohibición de la discriminación en Chile”, en Opinión Jurídica (18, № 36), pp. 57-85.

Añón Roig, María José (2013): “Principio antidiscriminatorio y determinación de la desventaja", en ISONOMÍA (№ 39), pp. 127-157.

(2016): "Discriminación racial: El racismo institucional desvelado", editado por Federico Arcos Ramírez, La justicia y los derechos en un mundo globalizado (Madrid, Dykinson), pp. 133- 165.

Arnardóttir, Oddný Mjoll (2002): "Equality and non-discrimination in the European Convention on Human Rights: towards a substantive approach". [Disponible en: https://bit.ly/3zPkGRa]. [Fecha de consulta: 23 mayo 2019].

Barranco Avilés, María del Carmen (2014): “Derechos humanos y vulnerabilidad. Los ejemplos del sexismo y el edadismo", eds. M. Carmen Barranco Avilés y Cristina Churruca Muguruza, Vulnerabilidad y protección de los derechos humanos (Valencia, Tirant lo Blanch), pp. 17- 44.

Barrère, María (2010): “La interseccionalidad como desafío al mainstreaming de género en las políticas públicas”, en Revista Vasca de Administración Pública (№ 87), pp. 225-252. 
Barrère María y Morondo, Dolores (2011): “Subordinación y discriminación interseccional: elementos para una teoría del derecho antidiscriminatorio", en Anales de la Cátedra Francisco Suárez (№ 45), pp.15-42

Bernal-Camargo, D.R. y Padilla-Muñoz, A.C. (2018): “Los sujetos de especial protección: construcción de una categoría jurídica a partir de la constitución política colombiana de 1991", en Revista Jurídicas (15, № 1), pp. 46-64.

Blaikie P; Cannon T; Davis I. y Wisner B. (1996): "Vulnerabilidad: el entorno social, político y económico de los desastres". Red de Estudios Sociales en Prevención de Desastres en América Latina, primera edición.

Brah, Avtar (2013): "Pensando en y a través de la interseccionalidad”, eds. Martha Zapata Galindo, Sabina García Peter y Jennifer Chan de Ávila, La interseccionalidad en debate. Actas del Congreso Internacional "Indicadores Interseccionales y Medidas de Inclusión Social en Instituciones de Educación Superior (Berlin, Freie Universität Berlin), pp. 14-20.

Catalá, Alicia (2010): “Discriminación múltiple por razón de género y pertenencia a minoría étnica. Jurisprudencia del Tribunal Europeo de Derechos Humanos", en Aequalitas: Revista jurídica de igualdad de oportunidades entre mujeres y hombres (№ 26), pp. 6-15.

Combahee River Collective. (2012): “Un Manifiesto Feminista Negro”, (Traducción Lucas Platero y Javier Sáez), editado por Lucas R. Platero Méndez, Intersecciones. Cuerpos y sexualidades en la encrucijada (Barcelona, Ediciones Bellaterra), pp. 75- 86.

Clérico, Laura y Aldao, Martín (2011): "Nuevas miradas de la igualdad en la jurisprudencia de la Corte Interamericana de Derechos Humanos: la igualdad como redistribución y como reconocimiento", en Lecciones y Ensayos (№ 89), pp. 141-179.

Díaz García, Iván (2013): "Ley chilena contra la discriminación: una evaluación desde los derechos internacional y constitucional”, en Revista Chilena de Derecho (40, № 2), pp. 635668.

Dulitzky, Ariel. (2007): "El Principio de Igualdad y No Discriminación. Claroscuros de la Jurisprudencia Interamericana”, en Anuario de Derechos Humanos (№ 3), pp. 15-32. 
Esparza, Estefanía (2019): “Algunas reflexiones críticas sobre el derecho a la igualdad como no discriminación en Chile”, en Revista Mexicana de Derecho Constitucional (№ 40), pp. 3-37.

Falcón y Tella, María José (2008): “Las acciones positivas en la legislación europea. El Derecho Alemán”, en Anuario de Derechos Humanos. Nueva Época (Vol. 9), pp. 245-266.

Ferrajoli, Luigui (2004): Derechos y garantías. La ley del más débil, 4. a edición, (Trad. Perfecto Andrés Ibañes y Andrea Greppi, Madrid, Trotta).

Fredman, Sandra y Szyszak Erika (1993): “The Interaction of Race and Gender” Eds. Bob Hepple \& Erika Szysczak, Discrimination: the limits of Law (London Mansell Publishing), pp. 214.126.

García, Lisa (2007): "Intersections of Inequality: Understanding Marginalization and Privilege in the Post-Civil Rights Era", en Politics and Gender (Vol. 3, № 2), pp. 232-248.

García Morillo, Joaquín (2013): “La cláusula general de igualdad” en López, Luis, Satrústegui, Miguel; García Joaquín; Espín, Eduardo: Pérez, Pablo, Derecho constitucional. 9.a ed. Volumen 1, (Valencia, Tirant lo Blanch).

Gómez, Gastón y Figueroa, Rodolfo (2000): “Discriminación contra la mujer y recurso de protección”, en Colección Informes De Investigación (№ 8, año 2), pp. 1- 21.

Granada Angulo, Lubi (2017): “Discriminaciones interseccionales percepciones de mujeres afrodescendientes en espacios de Educación Superior en Bogotá”, en Feminismo/s (№ 29), pp. 201-220.

Hannet, Sarah (2003): "Equality at the Intersections: The Legislative and Judicial Failure to Tackle Multiple Discrimination”, en Oxford Journal of Legal Studies (Vol. 23, № 1), pp. 65-86.

Jopia, Valeria y Labbé Natalia (2018): “Discriminaciones múltiples y la recepción en el Derecho Interno: el caso de Lorenza Cayuhán”, en Estudios Constitucionales (Año 16, № 1), pp.437452.

Jordan-Zachery, Julia S. (2007): “Am I a Black Woman or a Woman Who Is Black? A Few Thoughts on the Meaning of Intersectionality", en Politics \& Gender (Vol. 3, № 2), pp. 254263. 
La Barbera, María Caterina (2016): “Interseccionalidad, un “concepto viajero": orígenes, desarrollo e implementación en la Unión Europea”, en Interdisciplina (Vol. 4, № 8), pp.105122.

Lombardo, Emanuela y Verloo Mieke (2010): “La 'interseccionalidad' del género con otras desigualdades en la política de la Unión Europea”, en Revista Española de Ciencia Política ( $\left.\mathrm{N}^{\circ} 23\right)$, pp. 11-30.

Lousada Arochena, José Fernando (2017): “Discriminación múltiple: El estado de la cuestión y algunas reflexiones", en Revista derecho social Aequalitas: Revista jurídica de igualdad de oportunidades entre mujeres y hombres (№ 41), pp. 29-40.

Makkonen, Timo (2002): "Multiple, compound and intersectional discrimination: Bringing the experience of the most marginalized to the fore", en Institute for Human Rights. Abo Akademi University. [Disponible en https://bit.ly/2Vm3P9B]. [Fecha de consulta: 10 junio 2019].

Nogueira Alcalá, Humberto (2012): “Diálogo interjurisdiccional, control de convencionalidad y jurisprudencia del Tribunal Constitucional en período 2006-2011", en Estudios Constitucionales (Año 10, № 2), pp. 57-140.

Palacios Zuloaga, Patricia (2006): “La No Discriminación. Estudio” en Nash, Claudio (2013). Ed. Nicole Lacrampette Derechos humanos y mujeres: teoría y práctica (Santiago, Universidad de Chile, Facultad de Derecho, Centro de Derechos Humanos), pp. 13-29.

Pérez Goldberg, Patricia (2017): “Discriminación: “El caso de Lorenza Cayuhán”, en Revista de Ciencias Sociales (№ 70), pp. 75-94.

Platero Méndez, Raquel (2012): “Son las políticas de igualdad de género permeables a los debates sobre la interseccionalidad? Una reflexión a partir del caso español", en Revista del CLAD Reforma y Democracia (№ 52) Centro Latinoamericano de Administración para el Desarrollo Caracas, Venezuela, pp. 135-172.

Rey Martínez, Fernando (2008): “La discriminación múltiple, una realidad antigua, un concepto nuevo", en Revista Española de Derecho Constitucional (№ 84), pp. 251-283. 
(2017): “Igualdad y prohibición de discriminación: de 1978 a 2018”, en Revista de Derecho Político (№ 100, septiembre-diciembre), pp. 125-171.

Rodríguez Zepeda, Jesús (2007): “Qué es la discriminación y cómo combatirla?”, en Discriminación, Igualdad y Diferencia Política. Editado por Comisión de Derechos Humanos del Distrito Federal y Consejo Nacional para Prevenir la Discriminación, pp. 57-94.

Romero Pérez, Xiomara Lorena (2011): “Minorías marginadas, ocultas o invisibles”, en Revista Derecho del Estado (№ 26, enero-junio), pp. 153-173.

Saba, Roberto (2016): “Más allá de la igualdad formal ante la ley. ¿Qué les debe el Estado a los grupos desaventajados? (Buenos Aires, Siglo Veintiuno Editores).

Torbisco Casals, Neus (2005): “La institucionalización de la diferencia: algunas notas sobre desigualdad estructural y democracia”, en Los límites de la democracia, AAVV, (Buenos Aires, Editores del Puerto).

Tracey, Guillermo (2011): “Categorías sospechosas y control de constitucionalidad”, en Lecciones y Ensayos (№ 89), pp. 181-216.

Young, Iris Marion (2000): "Justice and the Politics of Difference, Princeton University Press" N.J. (Trad. Silvina Álvarez) La justicia y la política de la diferencia (ed. Cátedra, Madrid). (2011): “Responsabilidad por la justicia” (Madrid, Morata).

\section{Jurisprudencia citada}

Corte Interamericana de Derechos Humanos: Almonacid Arellano y otros vs. Chile, 26 septiembre 2006.

Tribunal Europeo de Derechos Humanos: B.S contra. España, 24 de julio de 2012.

Corte Interamericana de Derechos Humanos: Gonzales Lluy y otros vs. Ecuador, 1 septiembre 2015.

Corte Interamericana de Derechos Humanos: Trabajadores de la Hacienda Brasil Verde vs. Brasil (2016): 20 de octubre de 2016. 
Corte Interamericana de Derechos Humanos: Caso I.V. vs. Bolivia, de 30 de noviembre de 2016.

Corte Suprema: Unda Merino con fisco de Chile, (Recurso Casación), Rol 3750-2013, de 12 de agosto 2013.

Corte Suprema: Cayuhán Lorenza con Gendarmería de Chile, (apelación, recurso de amparo), Rol № 92795-2016, de 1 de diciembre de 2016.

Corte Suprema: Ponce Pérez con AFP plan vital S.A, (Apelación, recurso de protección), Rol № 73935-2016, de 24 enero 2017.

Comisión interamericana Derechos Humanos

Acceso a la justicia para las mujeres víctimas de violencia en las Américas (2007): Comisión Interamericana de Derechos Humanos, OEA/Ser.L/V/II. Doc. 68, 20 enero 2007.

Mujeres indígenas desaparecidas y asesinadas en Columbia Británica, Canadá (2014): Comisión Interamericana de Derechos Humanos, OEA/Ser.L/V/II. Doc. 30/14, 21 diciembre 2014.

Comités Naciones Unidas

Recomendación general № XXVII relativa a la discriminación de los romaníes (2000): Comité para la Eliminación de la Discriminación Racial (CERD), 57o período de sesiones.

Observación General № XX, La no discriminación y los derechos económicos, sociales y culturales (2009): Comité de Derechos Económicos, Sociales y Culturales (CESCR), 42ํㅜ período de sesiones.

Tratados internacionales

Pacto internacional Derechos Civiles y Políticos (1966): Asamblea General de Naciones Unidas, resolución 2200 A (XXI), de 16 de diciembre de 1966.

Convención Interamericana para Prevenir, Sancionar y Erradicar la Violencia contra la Mujer (1994): OEA Vigésimo cuarto periodo ordinario de sesiones de la asamblea general, 6 septiembre 1994. 
Declaración de Durban (2001): Conferencia Mundial contra el racismo, la discriminación racial, la xenofobia y las formas conexas de Intolerancia, Durban, Sudáfrica, 31 agosto al 7 septiembre 2001.

Convención Interamericana Contra Toda Forma de Discriminación e Intolerancia (2013) OEA Cuadragésimo Tercer Período Ordinario de Sesiones de la Asamblea General, 5 de junio de 2013.

Convención Interamericana sobre la Protección de los Derechos Humanos de las Personas Mayores (2015): OEA Cuadragésimo Quinto Período Ordinario de Sesiones de la Asamblea General, 15 de junio de 2015. 